\title{
Perbedaan Hasil Perawatan Wajah Untuk Kulit Berjerawat Dengan Menggunakan Masker Tradisional Temulawak Dan Temugiring Pada Siswa SMK Negeri 8 Medan
}

\author{
Tabita Tarigan $^{1)}$ Rohana Aritonang ${ }^{2)}$
}

\begin{abstract}
ABSTRAK
Penelitian ini bertujuan untuk (1) Hasil perawatan wajah untuk kulit berjerawat dengan menggunakan masker tradisional temulawak; (2) Hasil perawatan wajah untuk kulit berjerawat dengan menggunakan masker tradisional temugiring; (3) Hasil yang terbaik untuk kulit berjerawat dengan menggunakan masker tradisional temulawak dan temugiring. Lokasi penelitian SMK Negeri 8 Medan. Penelitian ini adalah penelitian metode eksperimen yakni untuk melihat perbedaan dua variabel yaitu Hasil masker tradisional temulawak $\left(X_{1}\right)$ dan Hasil masker tradisional temugiring $\left(X_{2}\right)$. Populasi penelitian ini adalah siswa kelas XI Jurusan Tata Kecantikan Kulit SMK Negeri 8 Medan sebanyak 35 siswa.Instrumen yang digunakan yaitu dengan menggunakan lembar pengamatan. Analisis data menggunakan statistik eksperimen yaitu dengan cara menghitung rata - rata skor atau mean $(\mathrm{M})$, Standart Deviasi(S) dan varians $\left(\alpha^{2}\right)$.

Dari hasil penelitian ditemukan hasil perawatan wajah setelah diberi perlakuan yaitu rata - rata skor 2,62 dan 2,32 dengan standar deviasi sebesar 0,297 dan 0,235, dan $F_{\text {hitung }}<F_{\text {tabel }}=4,03<6,39$. Pada taraf signifikansi 5\%.Berdasarkan hasil penelitian ini dapat disimpulkan bahwa terdapat perbedaan hasil perawatan wajah untuk kulit berjerawat dengan menggunakan masker tradisional temulawak dan temugiring.Di sarankan guru SMK Negeri 8 Medan agar memanfaatkan bahan tradisional untuk perawatan wajah kulit berjerawat.
\end{abstract}

\section{PENDAHULUAN}

SMK Negeri 8 Medan sebagai sebuah lembaga pendidikan dan latihan untuk tingkat menengah kejuruan yang beralamat di jalan Dr.Mansyur. SMK Negeri 8 Medan memiliki 4 kompetensi jurusan diantaranya adalah : Tata Boga, Tata Busana, Tata Kecantikan, dan Akomodasi Perhotelan. SMK Negeri 8 Medan memiliki visi yaitu : mewujudkan SMK Negeri 8 Medan sebagai lembaga diklat yang unggul dalam menghasilkan tamatan di bidang keahlian tata boga, tata busana, tata kecantikan, dan akomodasi perhotelan. Misi SMK Negeri 8 Medan yaitu: Menyiapkan sumber daya manusia yang terampil, kreatif, bertanggung jawab dan berwawasan luas sesuai bidang keahliannya dan berorientasi mutu di segala kegiatannya;
(2) Mengembangkan iklim belajar dan bekerja yang kondusif, kompetitif, dengan pemberdayaan potensi sekolah: guru, siswa, dan masyarakat yang dilandasi oleh keimanan, kejujuran, dan kedisplinan.

Dari observasi yang dilakukan di lapangan (Agustus,2014), terdapat 10 siswa yang memiliki kulit berjerawat yaitu siswa kelas XI Smk Negeri 8 Medan. Faktorfaktor yang menyebabkan kulit berjerawat pada siswa yaitu kurangnya menjaga kebersihan kulit, memakan makanan yang pedas, cuaca yang panas, dan pada waktu menstruasi. 
Perbedaan Hasil Perawatan Wajah Untuk Kulit Berjerawat Dengan Menggunakan Masker Tradisional Temulawak Dan Temugiring Pada Siswa SMK Negeri 8 Medan

METODE PENELITIAN

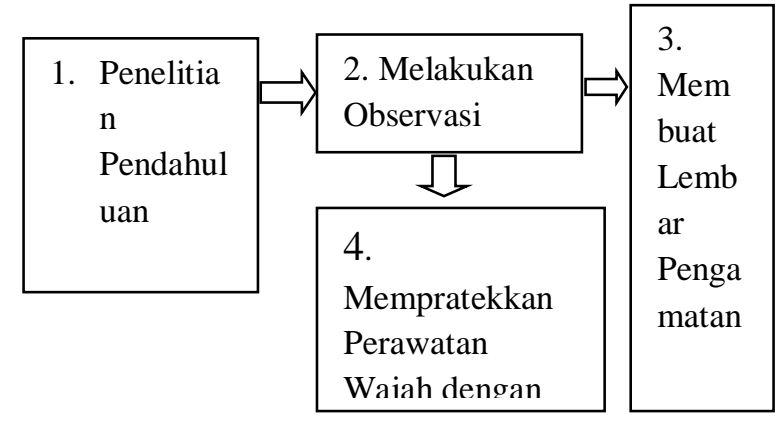

Teknik Analisis Data

Teknik analisis data yang digunakan untuk mengolah data adalah eksperimen dengan ketentuan rumus sebagai berikut :

\section{Uji Persyaratan Analisis}

Uji persyaratan analisis dilakukan untuk mengetahui apakah data ubahan berdistribusi memenuhi persyaratan analisis, yaitu apakah data ubahan berdistribusi normal memiliki varians homogen. Uji normalitas dilakukan dengan menggunakan uji liliefors dengan bantuan tabel sebagai berikut:

\begin{tabular}{|l|l|l|l|l|l|}
\hline No & $\mathrm{Xi}$ & $\mathrm{Zi}$ & $\mathrm{F}(\mathrm{Zi})$ & $\mathrm{S}(\mathrm{Si})$ & $\begin{array}{c}\mathrm{F}(\mathrm{Zi})- \\
\mathrm{S}(\mathrm{Si})\end{array}$ \\
\hline 1 & & & & & \\
\hline 2 & & & & & \\
$\mathrm{dst}$ & & & & & \\
\hline
\end{tabular}

Keterangan :

$\mathrm{Xi}=$ Skor yang diurutkan dari yang terkecil

$\mathrm{Zi}=\frac{\mathrm{X} \mathrm{i}-\mathrm{x}}{\mathrm{SD}}$

$\mathrm{X}=$ Skor rata - rata
$\mathrm{SD} \quad=$ Standar deviasi

$\mathrm{F}(\mathrm{Zi})=$ Dilihat dari daftar distribusi normal<1

$\mathrm{S}(\mathrm{Si})=$ Interval skor $<1$

$\mathrm{SD}=\frac{1}{N} \sqrt{N \sum X^{2}}-\left(\sum X\right)^{2}$

$\mathrm{N}=$ Jumlah sampel

$\sum x=$ Jumlah produk butir $\mathrm{x}$

Dari hasil uji liliefors berdasarkan tabel di atas diambil nilai Lo tertinggi lalu dibandingkan dengan Ltabel pada taraf signifikansi $5 \%$ jika Lo $<\mathrm{Lt}=$ data distribusi normal.

Selanjutnya untuk mengetahui apakah data ubahan penelitian memiliki varians homogen. Pengujian homogenitas varians dilakukan dengan dua data kelompok sampel atau lebih dilakukan dengan uji $\mathrm{F}$ dengan rumus :

$F_{\text {hitung }} \frac{\text { varians terbesar }}{\text { varians terkecil }}$

Jika $F_{\text {hit }}<F_{\text {tabel }}(\alpha)(\mathrm{db}=(\mathrm{n} 1-1)(\mathrm{n} 2-1)$ maka Ho diterima (data homogen)

Jika $F_{\text {hit }}>F_{\text {tabel }}(\alpha)(\mathrm{db}=(\mathrm{n} 1-1)(\mathrm{n} 2-1)$ maka Ho ditolak (data tidak homogen)

Sudjana , 2002

\section{Pengujian Hipotesis}

Uji hipotesis dilakukan dengan uji anava dua jalur,

Tabel .Total perlakuan anava satu jalur

\begin{tabular}{|c|l|l|l|}
\hline \multirow{2}{*}{ Faktor B } & \multicolumn{2}{|l|}{ Faktor A } & \multirow{2}{*}{ Total } \\
\cline { 2 - 3 } & $\boldsymbol{a}_{1}$ & $\boldsymbol{a}_{2}$ & \\
\hline$b$ & & & \\
\hline
\end{tabular}

Dari tabel diatas maka hitung $J K_{\text {tot }}$, $J K_{\text {ant }}, J K_{\text {dal }}, M K_{\text {dal }}$, dan $F_{h}$ seperti berikut ini : 
Perbedaan Hasil Perawatan Wajah Untuk Kulit Berjerawat Dengan Menggunakan Masker Tradisional Temulawak Dan Temugiring Pada Siswa SMK Negeri 8 Medan

1. Tentukan derajat bebas $(\mathrm{db})$ untuk setiap sumber keberagaman:

derajat bebas antar kelompok $=\mathrm{m}-1$

derajat bebas dalam kelompok $=\mathrm{N}-\mathrm{m}$

2. Hitung jumlah kuadrat antar kelompok $(J$ $K_{\text {ant }}$ )

$J K_{\text {ant }}=\frac{\left(\sum X_{1)^{2}}\right.}{n_{1}}+\frac{\left(\sum X_{2)^{2}}\right.}{n_{2}}-\frac{\left(\sum X_{\text {tot }}\right)^{2}}{N}$

3. Hitung jumlah kuadrat dalam antar kelompok $\left(J K_{\text {dal }}\right)$

$J K_{\text {dal }}=J K_{\text {tot }}-J K_{\text {ant }}$

4. Hitung menengah kuadrat antar kelompok $\left(M K_{\text {ant }}\right)$

$M K_{\text {ant }}=J K_{\text {ant }}$

$\mathrm{m}-1$

5. Hitung menengah kuadrat dalam kelompok $\left(M K_{\text {dal }}\right)$

$\left(M K_{\text {dal }}\right)=\frac{J K_{\text {dal }}}{N-m}$

6. Cari $F_{\text {hitung }}=\underline{M K_{\text {ant }}}$

$M K_{\text {dal }}$

Tabel .Ringkasan anava untuk rancangan penelitian 1x2

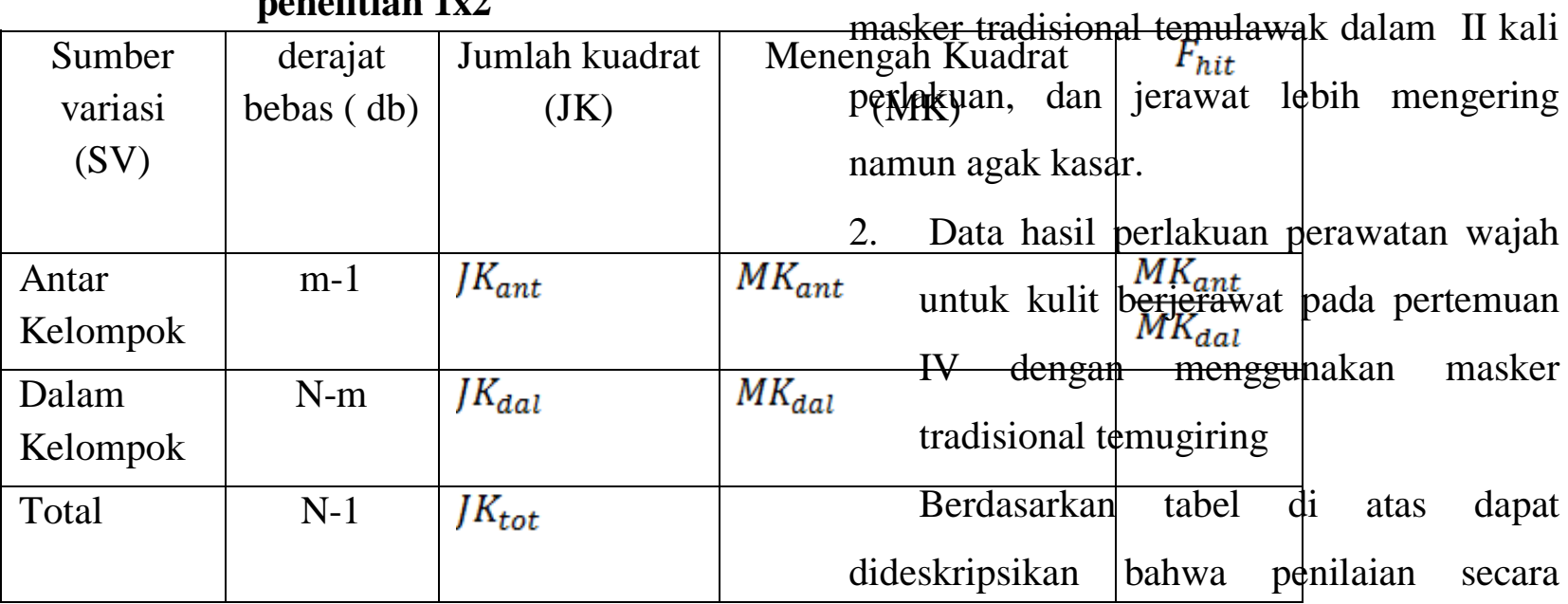

keseluruhan panelis memberikan skor 2,09-

2,56 hal ini berarti mendekati skor 2 bahwa

hasil warna merah kecoklatan, bentuk

HASIL DAN PEMBAHASAN

1. Deskripsi Penelitian

\begin{tabular}{|l|c|c|}
\hline \multirow{2}{*}{ Perlakuan } & \multicolumn{2}{|c|}{ Masker Tradisional } \\
\cline { 2 - 3 } & Temulawak & Temugiring \\
\hline Perlakuan I & 9,86 & 11,33 \\
\hline Perlakuan II & 8,26 & 10,19 \\
\hline
\end{tabular}

Hasil data penelitian diatas untuk lebih terperinci dapat dilihat pada lampiran 2 .

1. Data hasil perlakuan perawatan wajah untuk kulit berjerawat pada pertemuan II dengan menggunakan masker tradisional temulawak

Berdasarkan tabel di atas dapat dideskripsikan bahwa penilaian secara keseluruhan panelis memberikan skor 2,41 $-2,83$ hal ini berarti mendekati skor 3 yaitu warna jerawat mendekati warna merah keputihan, bentuk jerawat mengecil dan sedikit menonjol, terdapat sekitar 15 jerawat yang mengering setelah menggunakan ngah Kuadrat . hit bih mengering namun agak kasar. 
Perbedaan Hasil Perawatan Wajah Untuk Kulit Berjerawat Dengan Menggunakan Masker Tradisional Temulawak Dan Temugiring Pada Siswa SMK Negeri 8 Medan

jerawat masih terlihat bulat kecil dan sedikit menonjol, jerawat yang mengering 10 jerawat dan jerawat mengering namun sedikit menonjol.Perbedaan skor hasil perawatan wajah untuk kulit berjerawat yang dilihat dari tahapan perlakuan yang diberikan pada kulit wajah yang berjerawat dengan menggunakan masker tradisional temulawak dan temugiring dapat dilihat pada histogram berikut ini :

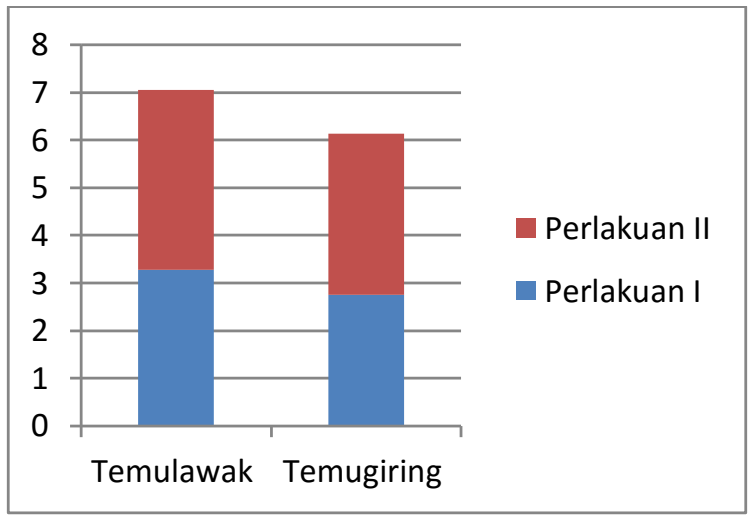

Histogram penilaian hasil perawatan wajah

HASIL UJI NORMALITAS

\begin{tabular}{|l|c|c|c|c|}
\hline Perlakuan & Temulawak & Temugiring & $\begin{array}{c}\mathbf{Z i} \\
\text { temulawak }\end{array}$ & $\begin{array}{c}\mathbf{Z i} \\
\text { temugiring }\end{array}$ \\
\hline $\begin{array}{l}\text { Perlakuan } \\
\text { I }\end{array}$ & 2,41 & 2,09 & 8,11 & 10,89 \\
\hline $\begin{array}{l}\text { Perlakuan } \\
\text { II }\end{array}$ & 2,83 & 2,56 & 9,52 & 9,89 \\
\hline \multicolumn{1}{|c|}{ Mean } & 2,62 & 2,32 & & \\
\cline { 1 - 2 } SD & 0,297 & 0,23 & & \\
\hline
\end{tabular}

\section{HASIL UJI HOMOGENITAS}

\begin{tabular}{|c|c|c|}
\hline \multirow{2}{*}{ Sampel } & \multicolumn{2}{|c|}{ Perlakuan } \\
\cline { 2 - 3 } & Temulawak & Temugiring \\
\hline 1 & 2,41 & 2,09 \\
\hline 2 & 2,83 & 2,56 \\
\hline Mean & 2,62 & 2,32 \\
\hline SD & 0,29 & 0,23 \\
\hline
\end{tabular}

\begin{tabular}{|l|l|l|}
\hline S2 & 2,576 & 0,32 \\
\hline
\end{tabular}

HASIL UJI HIPOTESIS

\begin{tabular}{|c|c|c|}
\hline \multirow[t]{2}{*}{ Perlakuan } & \multicolumn{2}{|c|}{ Masker Tradisional } \\
\hline & Temulawak & Temugiring \\
\hline & 2,41 & 2,09 \\
\hline & 2,83 & 2,56 \\
\hline Total & 5,24 & 4,65 \\
\hline Mean & 2,62 & 3,07 \\
\hline \multicolumn{3}{|c|}{$\begin{array}{l}\text { Dengan membandingkan } F_{\text {hitung }} \text { masing - } \\
\text { masing, maka diperoleh bahwa } F_{\text {hitung }}>\end{array}$} \\
\hline
\end{tabular}

\section{PENUTUP}

\section{A. KESIMPULAN}

1. Terdapat perbedaan yang signifikan antara hasil perawatan wajah untuk kulit berjerawat dengan menggunakan masker tradisional temulawak dan temugiring dengan $F_{\text {hitung }}<F_{\text {tabel }}, 4,03<6,39$

2. Hasil perawatan wajah untuk kulit berjerawat dengan menggunakan masker tradisional temulawak dan masker tradisional temugiring dapat dilihat dari perubahan rata - rata skor, standar deviasi dan varians masing - masing masker tradisional diberi perlakuan dengan rata - rata 2,62 dan 2,32 dengan standar deviasi 0,29 dan 0,23 
Perbedaan Hasil Perawatan Wajah Untuk Kulit Berjerawat Dengan Menggunakan Masker Tradisional Temulawak Dan Temugiring Pada Siswa SMK Negeri 8 Medan

3. Terdapat perbedaan hasil perawatan wajah dilihat dari jumlah jerawat yang berkurang pada masker tradisional temulawak dan temugiring dengan $F_{\text {hitung }}>F_{\text {tabel }}$ $(8,00>5,32)$

\section{B. IMPLIKASI}

Ada perbedaan hasil perawatan wajah dikarenakan jerawat dapat mengering setelah dilakukan perlakuan pada model dengan menggunakan masker tradisional temulawak dan temugiring berdasarkan pengujian hipotesis.Hal ini memberikan indikasi bahwa hasil perawatan wajah dengan menggunakan masker tradisional temulawak berbeda dengan temugiring, dan warna jerawat seperti merah keputihan namun warna jerawat lebih memerah setelah diberi perlakuan dengan menggunakan masker tradisional.

\section{SARAN}

Berdasarkan hasil penelitian di atas, ada beberapa saran yang diajukan :

1. Sebaiknya siswa yang berjerawat menggunakan masker tradisional temulawak sehingga jerawat lebih cepat mengering .

2. Diharapkan masker tradisional temulawak dan temugiring dapat diterapkan di lingkungan masyarakat, sebagai pemanfaatan bahan -bahan tradisional.

3. Bagi peneliti selanjutnya agar lebih memperhatikan kelemahan kelemahan dalam penggunaan bahan tradisional untuk lebih mencapai hasil yang lebih baik lagi.

\section{DAFTAR PUSTAKA}

Andy. (2009). Tips Menghilangkan Jerawat.Diakses pada 10 Juli 2014 dari http://darknessandy.blogspot.com/2012/02/9 -tips-menghilangkan-jerawat.html Aritonang, Rohana. 2010. Dasar Rias. Medan: Universitas Negeri Medan Boyke. (2012).Defenisi jerawat.Diakses pada 22 Agustus 2014 dari http://anggi05.wordpress.com/category/defin isi-jerawat/

Budi.2013. Tumpas Penyakit dengan 40 Daun dan 10 Akar Rimpang. Yogyakarta: Cahaya Jiwa 
Perbedaan Hasil Perawatan Wajah Untuk Kulit Berjerawat Dengan Menggunakan Masker Tradisional Temulawak Dan Temugiring Pada Siswa SMK Negeri 8 Medan

Chandra. (2011). Tingkatan Jerawat.Diakses pada $\quad 30 \quad$ Agustus 2014 dari http://chandraaulia.wordpress.com/2011/01/ 27/menghilangkan jerawat.html.

Ekel. 1981. Ilmu Pengetahuan Kulit. Yogyakarta : Cahaya Jiwa

Kusumadewi. 2002. Perawatan dan Tata Rias Wajah Wanita Usia 40+.Jakarta:Gramedia Pustaka Utama

Lina, Dessy. 2011. Kosmetika Tradisional.

Medan. Universitas Negeri Medan

Mahendra. 2005. Budidaya dan Manfaat

Temugiring. Jawa Tengah: Hasil Karya

Putra Nusantara

Mursito. (2003). Pengaruh Penambahan Kurkumin Dari Rimpang Temu Giring Pada Aktifitas Antioksidan Asam Askorbat Dengan Metode FTC.Jurnal.Akta Kimia Indonesia.Edisi Oktober, 2006:37-40 Nofianty,Tri. 2008. Pengaruh Formulasi Literatur Kosmetika. Jakarta: Universitas Indonesia

Pasarmaulim.(2011). Statistik Teori Aplikasi

Dalam Penelitian. Bandung:Tarsito

Pawang.(2012). 4 Tingkat Keparahan Jerawat.Diakses pada $20 \quad$ Juni

2014.http://carajerawatsembuh.blogspot.co

$\underline{\mathrm{m} / 2012 / 01 / 4 \text {-tingkat-keparahan- }}$

jerawat.html

Pipin. 2010. Masker Tradisional. Bandung:

Yrama Widya

Prapty, Desty. 2013. The Miracle of Herbs. Jakarta: Gramedia Pustaka Utama
Rannie. 2011. Kiat cantik dan Menarik Panduan Usaha Mandiri.Bandung: Yrama Widya

Ratna.(2013). Fungsi Keratinisasi. Diakses pada $\quad 07 \quad$ Mei $2014 \quad$ dari http://anggi05.wordpress.com/category/defin isi-jerawat/

Retno. 2002. Kiat Apik Menjadi Sehat Dan

Cantik. Jakarta: Gramedia Pustaka Utama

Santoso.2013. Industri Jamu

Tradisional.Jakarta: Gramedia Pustaka

Utama

Setiadi. 2007.Cantik Dengan Bahan

Tradisional.Jakarta: Gramedia Pustaka

Utama

Siregar. 1991. Jenis Jerawat.Universitas

Sumatera Utara: Referensi

Sudjana. 2002. Metode Statiska. Bandung.

Tarsito

Sugiyono.2013.Metode

Penelitian

Pendidikan.Bandung: Alfabeta

Tresna, Pipin. 2010. Modul 1 Dasar Rias

Perawatan Kulit Wajah (Facial). Bandung:

Universitas Pendidikan Indonesia

Widiyanto. 2012. SPSS For Windows.

Semarang: Badan Penerbit-FKIP UMS

Yuniarti, Titin. 2012. Ensiklopedia

Tanaman Obat Tradisional.Yogyakarta:

Media Press 